\title{
MOCK CIRCULATORY LOOPS USED FOR TESTING CARDIAC ASSIST DEVICES: A REVIEW OF COMPUTATIONAL AND EXPERIMENTAL MODELS
}

Femke Cappon ${ }^{1}$, Tingting $\mathrm{Wu}^{2}$, Theodore Papaioannou ${ }^{3}$, Xinli Dư ${ }^{1}$, Po-Lin Hsu², Ashraf W Khir ${ }^{1}$

${ }^{1}$ Department of Mechanical and Aerospace Engineering, Brunel University London, Uxbridge, UK

${ }^{2}$ Department of Mechanical and Electrical Engineering, Soochow University, Suzhou, China

${ }^{3}$ Biomedical Engineering Unit, First Department of Cardiology, Medical School, National and Kapodistrian University of Athens, Greece

Corresponding author Ashraf W Khir: Brunel Institute for Bioengineering, Brunel University, Kingston Lane, Uxbridge, Middlesex UB8 3PH, UK. E-mail address: ashraf.khir@brunel.ac.uk 


\begin{abstract}
Heart failure is a major health risk, and with limited availability of donor organs, there is an increasing need for developing cardiac assist devices (CADs). Mock circulatory loops (MCL) are an important invitro test platform for CAD's performance assessment and optimization. The $M C L$ is a lumped parameter model constructed out of hydraulic and mechanical components aiming to simulate the native cardiovascular system (CVS) as closely as possible. Further development merged MCLs and numerical circulatory models to improve flexibility and accuracy of the system; commonly known as hybrid MCLs. 128 MCLs were identified in a literature research until 25 September 2020. It was found that the complexity of the MCLs rose over the years, recent MCLs are not only capable of mimicking the healthy and pathological conditions, but also implemented cerebral, renal and coronary circulations, and autoregulatory responses. Moreover, the development of anatomical models made flow visualisation studies possible. Mechanical MCLs showed excellent controllability and repeatability, however, often the CVS was overly simplified or lacked autoregulatory responses. In numerical MCLS the CVS is represented with a higher order of lumped parameters compared to mechanical test rigs, however, complex physiological aspects are often simplified. In hybrid MCLs complex physiological aspects are implemented in the hydraulic part of the system, whilst the numerical model represents parts of the CVS that are too difficult to represent by mechanical components per se. This review aims to describe the advances, limitations and future directions of the three types of MCLs.
\end{abstract}




\section{INTRODUCTION}

As of April 2020, in the UK solely, 340 patients are on the active heart transplant list, while only 172 transplants are available. ${ }^{1}$ Cardiac Assist Devices (CADs) are an alternative solution to heart failure patients. $^{2}$ Implantable Ventricular Assist Devices (VADs) are used as a bridge-to-transplant or permanent support for severe heart failure patients with cardiogenic shock and multiple organ dysfunctions ${ }^{3}$ and have substantially improved survival-rates for patients who are awaiting heart transplantation. ${ }^{4}$ Due to recent technical advances of VADs, destination therapy became a genuine long-term solution for heart failure patients. ${ }^{5}$ However, serious adverse events remain high after VAD implementation: between 2015-2019 causes of death in patients with VAD support were, for example, due to multisystem organ failure (16.4\%), neurologic dysfunction (15.6\%) and heart failure $(12.5 \%){ }^{2}$ Thus, ongoing research is needed to enhance VADs as a solution to the increasing donor shortage.

The Mock Circulatory Loop (MCL) plays a key role in the design, development and in vitro assessment of VADs and other CADs (e.g. vascular stents, heart valves, and Intra-Aortic Balloon Pumps (IABP)). In vitro studies are preferred over in vivo studies when quantitative investigation and adoption of specific, controlled, physiological parameters are needed. Moreover, in vitro studies do not require ethical approval and are much more cost-effective than animal studies. Therefore, MCLs are widely used prior to in vivo studies. The MCL aims to mimic the structure and function of the native cardiovascular system (CVS) by providing a realistic test-bench for performance assessment. It simulates hemodynamic parameters like heart rate, ventricle contractility, peripheral resistance, arterial compliance, and fluid inertance under healthy and various degrees of pathological conditions. These parameters are adapted to obtain physiological pressure and flow waveforms. MCLs are employed to study, for example, the fluid balance between the systemic and pulmonary circulation of an adult patient ${ }^{6}$, the timing of IABP inflation ${ }^{7}$, the unloading effect of a rotary blood pump ${ }^{8}$ and to study the hemodynamics of artificial heart valves ${ }^{9}$, extracorporeal life support ${ }^{10}$ or biventricular assist devices. ${ }^{11}$

Three different types of MCLs exist: firstly, the mechanical MCLs (M-MCLs), which simulates the CVS using mechanical and hydraulic components. M-MCLs were the first type of MCLs developed, see Figure 1. M-MCLs represent the ventricles with hydraulic pumps, the arterial compliance by water and air-filled, reservoirs (or flexible tubes), and the resistance is simulated by obstructions of the flow path. M-MCLs can test various CADs and pathological conditions. However, the fixed design limits the range of applications.

Numerical models of the CVS develop in parallel to M-MCLs, in which the CVS is described with mathematical expressions. Numerical MCLs (N-MCL), that are reviewed in this paper are lumped parameter models. They have absolute reproducibility, controllability and are more flexible than $\mathrm{M}$ MCLs. However, they neglect or simplify physiological aspects and complex properties of the CVS (e.g. wave travel and turbulence).

Merging N-MCLs and M-MCLs defines a third group of MCLs: hybrid MCLs (H-MCLs). ${ }^{12}$ In an H-MCL the numerical and mechanical parts run alongside and communicate with each other in real-time using a numerical-hydraulic interface. The $\mathrm{H}-\mathrm{MCL}$ can describe cardiovascular characteristics using computer algorithms that are too difficult to represent with mechanical components and provides a hydraulic platform to connect the physical prototypes of CADs. Within the next few years, H-MCLs are likely to become an essential test-bench for CADs development.

[insert Fig. 1]

Baturalp and $\operatorname{Ertas}^{13}$ recently conducted a review of the driving system of MCLs. Furthermore, Shi et al. presented a comprehensive review of the build-up ${ }^{14}$ and general structure ${ }^{15}$ of MCLs. The focus of these reviews was on M-MCLs. Our review presents an overview of the three types of MCLs and will provide insights into the technological advances and features of the MCLs over the years. 
The first section presents a brief overview of the cardiovascular system. The second section explains computational modelling. The next section of the review outlines the methodology of the literature search. The main body of this review then describes the development of the three different types of MCLs. The conclusion draws on the limitation of the current systems and gives an outlook on the future directions of MCLs.

\section{THE CARDIOVASCULAR SYSTEM}

The MCL aims to replicate the function and structure of the native CVS as closely as possible. Briefly, the CVS comprises of the heart, the systemic vessels that carry the blood to peripheral organs, and the pulmonary vessels, that carry the blood to the lungs where it gets oxygenated. The contraction of the heart produces a pressure and flow wave that propagates along the arterial tree. The left and right side of the heart that supply the systemic and pulmonary circulation respectively, are a pulsatile pump composed of two chambers: the ventricles, the main pumping force, and the atrium, which provides the ventricle with blood. The left and right ventricles must overcome the systemic vascular resistance (SVR), and the pulmonary vascular resistance (PVR), respectively, to push blood through the aorta into the arterial bed.

The CAD to be studied mainly decides which features of the CVS are important to integrate in the MCL for performance assessment. VADs, biVADs or total artificial hearts (TAHs) require a model of the pulmonary and systemic circulation. The challenge of developing a TAH or VAD is to adequately maintain fluid balance between both circulations. The difficulties arise as part of the left ventricular output returns to, not the right, but left atria via the bronchial arteries, whereas the right ventricular output is completely directed towards the left atrium. Therefore, left ventricular output is higher than the right. Insufficient fluid balance of VADs or TAHs can lead to suction events which can lead to reduced cardiac output. To study the performance of an IABP the implementation of the coronary circulation and its autoregulation is recommended. The coronary flow is highest during diastole, as during systole the ventricle constricts the coronary artery. The IABP aims to increase mean arterial pressure and myocardial perfusion during diastole. It is positioned inside the aorta, and therefore, to study the performance in an MCL a model of the aorta is required.

\section{REGULATORS OF THE BLOOD FLOW IN THE CARDIOVASCULAR SYSTEM}

Multiple regulatory mechanisms of the CVS are able to increase cardiac output or redirect blood towards active tissue. The volume of blood flow of the heart is regulated by the heart's intrinsic ability to adapt to increasing volume of inflowing blood, known as the Frank-Starling mechanism. The FrankStarling mechanism states that the greater the heart muscle is stretched during filling, the greater is the force of contraction and the greater the stroke volume. The Frank-Starling mechanism enhances venous return to the heart, for example, during exercise. Moreover, the heart can compensate for the reduced cardiac output in heart failure patients to maintain sufficient organ perfusion.

The CVS can also regulate blood flow by redirect the blood towards active tissue, for example, when exercising more blood is needed in the skeletal muscles, heart and lungs. The autonomic nervous system plays a key role in the regulation of vascular homeostasis. The heart rate can be changed by the sympathetic and parasympathetic nerves, which respond to a fluctuation in mean arterial pressure. The sympathetic nervous system innervates small arteries, which can constrict arterioles throughout the body. This increases the blood volume in larger arteries and as a result, mean blood pressure. Sympathetic nerves also innervate the veins, controlling the venous reservoir and heart preload. The parasympathetic nerves innervate the heart, they can decrease heart rate and ventricular contractility.

The most well-known nervous response mechanism is the baroreceptor reflexes. The baroreceptors are primarily found in the sinuses of the aorta and the carotid arteries. The baroreceptors respond to a change of stretch in the blood vessel. Increased blood pressure will stretch the baroreceptors more 
tightly, initiation action potentials at a higher rate. The sympathetic nerves will, in a response to the increase action potentials, dilate peripheral arterioles and thus reducing the blood pressure. The baroreceptors in the venae cavae and right atrium monitor the blood pressure as the blood returns from the systemic circulation, ensuring that blood ejected by the left ventricle is equal to the blood flow into the right atrium. When blood flows into the right atrium is more rapidly than the ejected blood of the left ventricle, the arterial receptors will increase the cardiac output until homeostasis is achieved. A schematic overview of the reaction of the baroreceptors to a change in mean arterial blood pressure is given in Figure 2. The baroreceptors can detect even the slightest change in pressure, which is especially important when a person stands up after laying down. The falling pressure at the baroreceptor elicits an immediate reflex to compensate for the decrease in pressure in the cerebral circulation and upper body.

[Insert Fig. 2]

\section{COMPUTATIONAL MODELS OF THE CARDIOVASCULAR SYSTEM}

The CVS can be modelled computationally from OD to 3D models depending on the aims and accuracy of the study. In Figure 3, the different dimensional models are represented. OD models, also known as, lumped parameter models reduce the components of the CVS into electrical elements. ${ }^{16,17} 1 \mathrm{D}$ models of the CVS are able to describe the pulse wave transmission within the vasculature, and can be used to study, for example, the blood flow around stents. ${ }^{18} 2 \mathrm{D}$ models can be used to study the local flow velocity in axisymmetric domain, for example, to study prosthetic valves. ${ }^{19}$ With $3 \mathrm{D}$ models, complex flow patterns can be studied, however, they are computationally very demanding. ${ }^{20}$

Hales was the first one in 1733 to introduce a conceptual lumped parameter model of the arterial tree. He observed that the variation of pressure in the arterial system is related to the elasticity of large arteries. Weber was the first to compare the elasticity of the arteries with the Windkessel, in which the pulsatile pump is damped by an air chamber. Frank was the first to mathematically describe the arterial response with a so-called two-element Windkessel model, using an electrical resistor and a capacitor to represent the SVR and the total arterial compliance, respectively. ${ }^{21}$ Three and fourelement Windkessel models were later developed to increase the accuracy of the impedance. ${ }^{22}$ Although the Windkessel elements do not simulate a specific vessel, they demonstrate good arterial impedance over a wide range of frequencies of the physiological heart rate. ${ }^{23}$

[insert Fig 3.]

\section{METHODS}

The literature is researched for MCLs of the CVS from the earliest possible start date until 25 September 2020 in SCOPUS. The search focusses on English peer-reviewed articles and conference papers.

The following search string: 'Mock Circulatory Loop OR Mock Circulatory System AND Cardiac Assist Device OR Ventricular Assist Device OR Biventricular Assist Device OR Total Artificial Hearts OR Mechanical Heart Valves OR Intra-Aortic Balloon Pump' identified the start set of papers. Backward reference searching identified other relevant papers, see Figure 4.

[Insert Fig. 4]

This paper solely includes N-MCLs of lumped parameter models. For reasons of space, numerical models that were exclusively used to study wave phenomena and not CADs performance were not addressed in this paper.

MOCK CIRCULATORY LOOPS: EARLY BEGINNINGS 
The M-MCLs adapted lumped parameter modelling into a physical test rig: electrical components were replaced by their hydraulic equivalents. A typical $\mathrm{M}-\mathrm{MCL}$ set up is illustrated in Figure 5 . The compliance of vessels was modelled by Windkessel chambers, a closed water reservoir with a trapped volume of air above the water level ${ }^{24-26}$, occasionally using spring capacitors ${ }^{27,28}$, or flexible tubes. ${ }^{29,30}$ The resistance of arteries was modelled by adding an obstruction in the flow path using, for example, swing check valves ${ }^{25}$ or throttles ${ }^{9}$, which mimic vasoconstriction. The inertance of the system is dependent on the fluid density and the tube's dimensions.

[Insert Fig. 5]

Preliminary work on M-MCLs was focused on testing artificial heart valves ${ }^{26,31}$ and occasionally TAHs. ${ }^{25,32,33}$ Donovan et al. developed a compact $\mathrm{MCL}$ in which the systemic and pulmonary circulations were simulated using a two-element Windkessel model ${ }^{25}$, adopted by many others. ${ }^{33-37}$ They were the first ones to attempt implementation of a simplified version of the baroreceptor response; SVR and PVR were automatically set using bellow operated valves. ${ }^{25}$

The abstracted Windkessel models of the CVS in M-MCLs provided an important in vitro test platform for artificial blood pumps and heart valves. However, it does not allow the study of wave propagation, a limitation of using Windkessel modelling. Reul et al. ${ }^{38}$ were early pioneers in the development of a hydromechanical model of the arterial systemic circulation with approximated geometry and elastic properties of arteries. Although the model could not be used for CAD's performance assessment, it is a valuable in vitro tool to study haemodynamic properties of the arterial system.

\section{ADVANCES OF THE MOCK CIRCULATORY LOOPS}

\section{COMPUTER CONTROLLED DRIVING SYSTEMS}

Pneumatic ${ }^{26,39}$ and hydraulic ${ }^{31,40}$ pumps were used to drive early M-MCLs. To improve the reliability and comparability of M-MCLs, Verdonck et al. ${ }^{41}$ developed a computer-controlled in vitro model of the left heart for testing artificial heart valves. The silicon models of the left atrium and ventricle were placed within a water-filled housing, where the amount of pressure was controlled by a feedback system. The system was able to regulate left arterial filling pressure and, arterial and ventricular contraction, relaxation and heart rate. Also Left Ventricular Assist Devices (LVAD) have been used to generate realistic flow conditions controlled by a pneumatic apparatus. ${ }^{42}$

By introducing computer-controlled ventricles in the $\mathrm{M}-\mathrm{MCL}$, researchers gained the ability to alter cardiac output which allowed simulation of exercising conditions ${ }^{43-45}$ and pathological conditions such as congestive left heart failure ${ }^{39,46-51}$, right heart failure ${ }^{46}$, valve regurgitation ${ }^{52,53}$ and cardiac arrhythmias. ${ }^{54}$ Timms et al. ${ }^{55}$ used a pneumatic ventricle in an $\mathrm{M}-\mathrm{MCL}$ to simulate normal and heart failure at rest by adjusting mean arterial pressure, heart rate, contractility, SVR, PVR and arterial compliance. Cardiac output was reduced from $5.15 \mathrm{~L} / \mathrm{min}$ to $2.7 \mathrm{~L} / \mathrm{min}$ for healthy and left heart failure patients, respectively. The M-MCL was later used for VADs performance assessment. ${ }^{56,57}$ Similar conditions were reproduced by Pantalos et al. who manipulated driveline pressure and SVR resulting in a reduction of cardiac output from $5.0 \mathrm{~L} / \mathrm{min}$ to $3.0 \mathrm{~L} / \mathrm{min} .{ }^{27}$ Whilst Tsuboko et al. ${ }^{58}$ simulated right heart failure by regulating the atrioventricular interaction. Similar heart conditions were simulated in $\mathrm{N}-\mathrm{MCLs}{ }^{59}$, by reducing the compliance of the left ventricle.

\section{FRANK STARLING MECHANISM}

The Frank-Starlings mechanism was implemented into MCLs, by using the computer controllable ventricles. ${ }^{27,60,61} \mathrm{MCLs}$ including Frank-Starling mechanisms describe the interaction of the CADs with the CVS more closely ${ }^{62}$, whilst MCLs without preload and afterload response will produce unphysiological results. ${ }^{63}$ Early researchers implemented the Frank-Starling mechanism ${ }^{17,63-66}$ using the time-varying elastance model of Suga-Sagawa. ${ }^{67}$ Baloa et al. ${ }^{63}$ were among the firsts to implement this elastance model into an M-MCL. In this model, the elastance of the left ventricle is linearly related 
to ventricle volume and pressure. Baloa et al. ${ }^{63}$ reported a left ventricular elastance (i.e. the gradient of the end-systolic-pressure-volume curve) in the range of $2.14 \mathrm{mmHg} / \mathrm{ml}$ to $2.27 \mathrm{mmHg} / \mathrm{mL}$. Yokoyama et al. ${ }^{68}$ reported a linear elastance curve ranging from 1.75 to $0.56 \mathrm{mmHg} / \mathrm{ml}$ in their M$\mathrm{MCL}$, which can simulate healthy and heart failure conditions.

Burkhoff et al. ${ }^{69}$ questioned the assumption of the linear end-systolic-pressure-volume relationship in humans and noted that the time-varying elastance model inadequately describes the contractility of the left ventricle under diseased and cardiac support conditions. Furthermore, Vandenberghe et al. showed in an in vivo experiment that the time-varying elastance model insufficiently represented the left ventricle under mechanical support. ${ }^{70}$ Moreover, in MCLs using the linear elastance model ${ }^{63,64,71}$, the end-systolic-pressure-volume curve crosses the volume axis at a negative value, which suggests a negative unstressed ventricle volume.

Colacino et al. ${ }^{72}$ adapted the linear time-varying elastance model to a non-linear elastance variant and proved through a numerical and experimental validation that the non-linear elastance model can simulate the preload and afterload sensitivity of the natural ventricle more closely. Other researchers used a natural logarithmic elastance model ${ }^{73}$ and look-up tables. ${ }^{16}$

\section{PHYSICAL ANATOMICAL MODELS}

In parallel with the development of the mock ventricles, researchers implemented anatomical models for flow visualisation studies and higher-order Windkessel models of the systemic and pulmonary circulations. Five-element Windkessel models were introduced to simulate both systemic and pulmonary circulations. ${ }^{74}$ Anatomical models of arterial beds ${ }^{7,75}$ and pulmonary trunks ${ }^{76}$ were developed to study haemodynamics of CADs. Patient-specific left ventricles were developed to assess intraventricular balloon pump ${ }^{77}$ and for in vitro flow visualisation studies ${ }^{78-81}$ Several studies include anatomical models of the aortic arch ${ }^{78,82,83}$, for example, Litwak et al. used an anatomical model of the ascending and descending aorta to study the aortic blood flow of continues flow and pulsatile flow VADs. ${ }^{84}$ Geier et al. ${ }^{82}$ used an aortic model to study different cannulation types of extracorporeal membrane oxygenation. And Peter et al. ${ }^{83}$ developed an anatomical model of the aorta including renal circulation to study wave travel.

More complete anatomical models of the systemic circulation have been developed by Kolyva et al. ${ }^{7}$ and Gehron et al. ${ }^{10}$ Kolyva et al. tested an IABP on an M-MCL with an anatomical model of the aorta and twelve of its largest branches. ${ }^{7,85}$ Local compliance and resistance were simulated using syringes of varying air volume and capillary tubes of different sizing at the outlet of the branches. Gehron et al. ${ }^{10}$ made a life-sized arterial bed of the venous and arterial circulation which allowed visualisation and quantification of flow phenomena of the CVS under extracorporeal life support. In this study the local compliance values could not be changed; however, resistance could be adjusted using variable Hoffman clamps which increased or decreased vessels diameter.

Refinement of the anatomical models of the pulmonary circulation was achieved by Knoops et al. ${ }^{76}$, Mueller et al. ${ }^{86}$, and D'Souza et al. ${ }^{87}$. Knoops et al. ${ }^{76}$ analysed the pulmonary hemodynamics by recreating an anatomical model of the pulmonary trunk with two generations of bifurcations. Their research showed the possibility of recreating patient- and pathology-specific models for haemodynamic investigations. Mueller et al. ${ }^{86}$ developed a pulmonary M-MCL with an anatomical model of the right heart to study the effects of CADs on the pulmonary circulation. The M-MCL was able to mimic a healthy pulmonary condition, mild and severe pulmonary hypertension and right heart failure. D'Souza et al. ${ }^{87}$ recreated a patient-specific 3D model of the proximal pulmonary artery used as a vascular test device. The model was evaluated in an M-MCL of the pulmonary circulation to evaluate hemodynamics. The pulmonary circulation has been redefined in a computational model by King et al ${ }^{88}$ In this study, a computational Windkessel model was developed to simulate patientspecific pulmonary conditions. 


\section{CORONARY, CEREBRAL AND RENAL CIRCULATION MODELS}

Another important development of $\mathrm{MCL}$ is the implementation of the coronary circulation. Geven et al. ${ }^{89}$ were among the firsts to accurately mimic this. The native coronary circulation supplies the heart muscle with blood during diastole, whereas in systole the coronary vessels are compressed due to the high ventricular pressure. The heart can regulate the amount of blood flow into the coronary arteries via vasoconstriction or vasodilation. Geven et al. ${ }^{89}$ simulated the coronary vessel with a tube that collapses under ventricular pressure. The autoregulation of the coronary blood flow was presented as a clamp between the myocardial circulation and the coronary artery. Other researchers simulated the coronary circulation using a dynamic resistor in $\mathrm{M}-\mathrm{MCLs}{ }^{27}$ or in N-MCL by connecting left ventricle output with right atrium input..$^{90,91}$

Rezaienia et al. ${ }^{92,93}$ implemented the coronary circulation with autoregulatory mechanism and aortic anatomical model in an M-MCL. The M-MCL also included the hemodynamic response of the cerebral autoregulation while operating a mechanical circulatory support device in the descending aorta. The dilation and constriction of the cerebrovascular system and coronary system was mimicked with pinch valves. Similar techniques have been used to simulate the autoregulation of the renal circuit in $\mathrm{M}-\mathrm{MCL}$ as well. ${ }^{94}$

More recently, Gregory et al. ${ }^{95}$ managed to replicate physiological accurate waveforms with an M$\mathrm{MCL}$ that simulates systemic, pulmonary, cerebral and coronary circulations. The hemodynamic response of the M-MCL was validated using impedance cardiography data from healthy humans. The Frank-Starling response of the ventricles and the cerebral and coronary autoregulation were included. Furthermore, Clark et al. ${ }^{96}$ introduced the cerebral circulation in an N-MCL and M-MCL to study the effect of thromboembolism and Bozkurt ${ }^{97}$ modelled the cerebral circulation including the circle of Willis in an N-MCL.

\section{HYBRID MOCK CIRCULATORY LOOPS}

Numerical models of the CVS form the basis of the H-MCL, part of the model is presented by a hydraulic ${ }^{98}$ or an electrical section. ${ }^{99,100}$ The difficulty in the development of H-MCLs is achieving a fast and accurate numerical-physical interface, i.e. the interaction between the numerical and physical model and the CAD. This interaction is achieved with sensors, actuators and fast responding control systems. In electrical-numerical MCLs, the interface is achieved by voltage-controlled current and voltage generators. ${ }^{101}$ Ferrari et al. created a numerical-hydraulic interface using DC motor driven gear pumps; atrial and arterial pressure were acquired from the hydraulic circuit and are used as two input variables for the numerical part. ${ }^{100}$ Output flow is computed in the numerical model and sent to a DC motor and servo amplifier to control the flow of the gear pump in the hydraulic circuit. The same interface has been adopted by others. ${ }^{102}$ This H-MCL was used to test VADs and IABPs, in which the CADs were connected to a physical arterial tree or aorta. ${ }^{29,98}$

Alternatively, Ochsner used two pressure-controlled reservoirs and a flow probe as a numericalhydraulic interface to test TAHs. ${ }^{103}$ This interface is similar to others, instead, SVR was adjusted to elicit changes in vasculature pressure. ${ }^{104-106}$ Recently, Mirzaei et al. ${ }^{107}$ studied the coupling of a physical experiment with multiple branches with a lumped parameter computer simulation. The numericalhydraulic interface has been tested to show its applicability, however, has not been used to study CADs yet. Others have developed an H-MCL to test cardiac compression devices; an apparatus that wraps around the heart to provide beating assistance. ${ }^{108,109}$ The physical part of the $\mathrm{H}-\mathrm{MCL}$, mechanical ventricles, interacted with a numerical model of the CVS. The contraction of the CAD is measured with a force sensor, which is used as input to the numerical model. The computational model uses the force measurement to calculate the cardiac output and venous return of the heart. The diameter of the simulated ventricles was calculated, from the cardiac output and venous return, and adjusted in the physical system using a swing-arm actuator. 
The Frank-Starling mechanism has also been widely adopted in $\mathrm{H}-\mathrm{MCL}$ using Sagawa's ${ }^{67}$ variable elastance model ${ }^{100}$ or using a time-varying wall stress function. ${ }^{108}$ Ochsner et al. ${ }^{103}$ used the nonlinear elastance model of Colacino et al. ${ }^{110}$ in their H-MCL, while Hanson et al. ${ }^{108}$ used a numerical heart model of Urbaszek and Schaldach. ${ }^{111} \mathrm{H}-\mathrm{MCL}$ were also able to simulate pathological states, such as reduced left ventricular elastance ${ }^{29,101,112,113}$ and reduced ventricular contractility. ${ }^{103,108}$

\section{BARORECEPTOR RESPONSE}

Ochsner et al. ${ }^{103}$ evaluated the performance of VADs on an H-MCL with baroreceptor response. The baroreceptor response adapted SVR and PVR when the pressure in the arterial system changed while keeping the heart rate constant. Fresiello et al. ${ }^{114}$ studied IABP timing on baroreceptor activity and the VAD's performance ${ }^{115}$ with an H-MCL. The baroreceptor response was based on the mathematical description by Ursino ${ }^{116}$, change in mean pressure affected heart rate, SVR and venous volume. Cuenca-Navalon et al. used an H-MCL to study TAHs which included a numerical model of the baroreceptor response ${ }^{117}$ in which SVR and venous volume were adopted to maintain mean arterial pressure. Heart rate changes and contractility were not included in this model, as the TAH to be tested should be able to replicate these native feedback mechanisms.

The baroreceptor response has been studied in M-MCLs as well. Mushi et al. adopted Ursino's model 118 into a continuous flow M-MCL. ${ }^{119}$ The computational model, calculated heart rate, ventricular contractility and SVR from mean arterial pressure. Heart rate and ventricular contractility were changed in the physical model by adapting the speed of the centrifugal pump. SVR was adjusted with a pressure valve. ${ }^{120}$ Jansen-Park et al. managed to fully implement the Frank-Starling mechanism and baroreceptor response into an M-MCL. ${ }^{121}$ The mean arterial pressure was regulated by changing the heart rate, contractility, SVR and unstressed venous volume. The baroreflex response implemented by Vaes et al. ${ }^{122}$ was based on a mathematical model by van Roon et al. ${ }^{123}$ in which the baroreceptor response readjusted systemic pressure by changing the heart rate.

Lastly, Bozkurt et al. ${ }^{124}$ investigated their newly developed continues flow LVAD using an N-MCL including baroreceptor response and healthy and pathological hemodynamics. Similarly, Bonnemain et al. ${ }^{125}$ used an N-MCL including baroreceptor response to study the hemodynamics of a continues flow LVAD on the location of the anastomosis. An overview of MCLs that included the baroreflex mechanism is given in Table 1.

Table 1: Overview of the baroreflex mechanisms implemented in MCL. The table specifies which parameters of the baroreflex mechanism are considered.

\section{Feedback Mechanism}

\begin{tabular}{|c|c|c|c|c|c|}
\hline First Author & Type & Contractility & Resistance & $\begin{array}{l}\text { Unstressed } \\
\text { volume }\end{array}$ & Heart rate \\
\hline F.M. Donovan 25 & M-MCL & Not Considered & Considered & Not Considered & Not Considered \\
\hline X. Ding ${ }^{126}$ & $\mathrm{~N}-\mathrm{MCL}$ & Not Considered & Considered & Not Considered & Considered \\
\hline M. Vaes ${ }^{122}$ & M-MCL & Not Considered & Not Considered & Not Considered & Considered \\
\hline F.M. Colacino ${ }^{110}$ & $\mathrm{M}-\mathrm{MCL}$ & Not Considered & Considered & Not Considered & Not Considered \\
\hline S. Mushi ${ }^{119}$ & $\mathrm{M}-\mathrm{MCL}$ & Considered & Considered & Not Considered & Considered \\
\hline S. Bozkurt ${ }^{124}$ & N-MCL & Not Considered & Not Considered & Not Considered & Considered \\
\hline J. Bonnemain ${ }^{125}$ & $\mathrm{~N}-\mathrm{MCL}$ & Considered & Considered & Considered & Considered \\
\hline G. Ochsner ${ }^{103}$ & $\mathrm{H}-\mathrm{MCL}$ & Not Considered & Considered & Considered & Not Considered \\
\hline $\begin{array}{l}\text { E. Cuenca- } \\
\text { Navalon }{ }^{117}\end{array}$ & $\mathrm{H}-\mathrm{MCL}$ & Considered & Considered & Considered & Considered \\
\hline L. Fresiello 114 & $\mathrm{H}-\mathrm{MCL}$ & Considered & Considered & Considered & Considered \\
\hline S. Schampaert ${ }^{127}$ & M-MCL & Not Considered & Not Considered & Not Considered & Considered \\
\hline S.H. Jansen-Park ${ }^{121}$ & M-MCL & Considered & Considered & Considered & Considered \\
\hline A. Petrou ${ }^{6}$ & $\mathrm{H}-\mathrm{MCL}$ & Considered & Considered & Considered & Considered \\
\hline
\end{tabular}




\section{DISCUSSION AND CONCLUSION}

Ever since the development of one of the first $\mathrm{MCL}^{32}$, their numbers and complexity rapidly rose over the years. MCLs play a key role in the development of a wide range of CADs. The MCLs's repeatability, flexibility and controllability make it a valuable platform to access CADs performance preliminary to in vitro studies. An increasing number of researchers have developed a system which is capable of reproducing a wide variety of patient conditions, including rest ${ }^{55}$, exercise ${ }^{44}$, different degrees of heart failure ${ }^{50,128}$, hypertension ${ }^{46}$ and valve insufficiencies. ${ }^{6}$ The recent study of Gregory et al. ${ }^{95}$ showed the excellent controllability and flexibility of the M-MCL. They studied the hemodynamics of simulated patients in resting, exercise and left heart failure conditions with and without ventricular support. However, the M-MCL lacked implementation of the baroreceptor response. Alternatively, Shi et al. ${ }^{17}$ studied the hemodynamics responses of different VADs in their N-MCL, but the numerical representation of the VAD does not allow for the study of complex hemodynamic effects. Thus, the solely hydraulic or computer-based platform does not always provide the flexibility that is required for a full performance assessment of CADs.

Table 2: Comparison table between the different MCLs.

\begin{tabular}{r|c|c|c|} 
& M-MCL & N-MCL & H-MCL \\
\hline High flexibility & X & $\checkmark$ & $\checkmark$ \\
Compact & X & $\checkmark$ & $\checkmark$ \\
\hline Physical prototype & $\checkmark$ & X & $\checkmark$ \\
Numerical prototype & X & $\checkmark$ & $\checkmark$ \\
\hline High reproducibility & X & $\checkmark$ & $\checkmark$ \\
\hline Complex hemodynamic effects & $\checkmark$ & $X$ & $\checkmark$
\end{tabular}

The hybrid platform allows interaction between the physical prototype and the numerical model of the CVS. This gives the advantage to use the hybrid platform over the solely mechanical or computerbased ones, a comparison between the systems is made in Table 2. The H-MCL of Petrou et al. ${ }^{6}$ showed the unique versatility of the hybrid platform. The numerical part of the $\mathrm{H}-\mathrm{MCL}$ can easily be changed from the native CVS to the Fontan circulation. Moreover, the mechanical valves can be removed, which makes the hybrid platform sufficient to study both biVADs and TAHs. However, the numerical models used by Petrou et al. ${ }^{6}$ lack validation, due to the absence of relevant clinical data.

The lack of validation is a recurring problem in mock circulatory studies. Often, researchers compare their static hemodynamic magnitudes against a range defined in the literature. For example, Mueller et al. compared their static hemodynamic parameters against a range of literature data from clinical and mock circulatory studies. ${ }^{86}$ In another study, the effect of arterial compliance on IABP performance was studied both in an MCL and in patients. ${ }^{129}$ However, it is important to evaluate the time response of the MCL as well, to study the performance of CADs during postural changes or exercise. ${ }^{95}$ This problem has only recently been recognised and addressed in the study of Gregory et al. ${ }^{95}$ who validated their acquired data from an M-MCL against clinical data. However, clinical data of pathological conditions was not available to them, and thus validation has only been done for healthy patients. A complete validation of an MCL is still absent in the available literature.

MCLs have been developed with additional subparts of the CVS such as the coronary, carotid and renal circulations. ${ }^{89,95,115,130}$ By expanding the $\mathrm{MCL}$, more physiological parameters can be investigated such as renal perfusion, which often leads to complications in patients with LVAD. ${ }^{131}$ Moreover, a module 
of the coronary circulation would allow evaluation of specific pathologies like myocardial infarction. ${ }^{89}$ Some MCLs only consider the left heart and systemic part of the CVS ${ }^{48,121,132}$ or the pulmonary circulation ${ }^{86}$, however, since a CAD interacts with the entire CVS, it is essential to model the complete circulation. Moreover, it is important to study the fluid balance between the pulmonary and the systemic circulation for physiological and pathological states. ${ }^{133}$ The cerebral circulation has solely been modelled in an N-MCL ${ }^{134}$ a hydraulic representation of it is up to this date limited to only the carotid arteries. A hydraulic model of the cerebral circulation would provide valuable insight into the interaction between the CAD and the cerebral circulation.

The regulatory mechanisms of the renal and cerebral arteries have only been partly implemented into a few MCLs. ${ }^{95,135}$ The renal arteries can constrict afferent arterioles, reducing renal blood flow. The effect of CAD on renal pathology is complex and not yet well understood. ${ }^{136} \mathrm{An} \mathrm{MCL}$ could be used as a tool to understand the hemodynamics of the renal circulation. Furthermore, the brain responds to an increase in carbon dioxide or hydrogen ions, which causes dilation in the cerebral vessels, allowing the waste products to wash out. This autoregulatory mechanism has not been assessed in MCLs yet.

The Frank-Starling mechanism has been implemented in several MCLs $65,115,137,138$, however, in some MCLs this mechanism is still absent, resulting in unrealistic representations of the response of the native heart. ${ }^{10,44,104}$ Moreover, the linear approximation of the elasticity of the heart seems to be outdated and needs to be replaced with a non-linear variant. ${ }^{72}$ The baroreceptor response, which affects heart rate, contractility, venous volume and SVR, has been introduced in MCLs as well. ${ }^{103,119,121}$ Most of the MCLs simulating the baroreceptor response kept the heart rate constant ${ }^{139,140}$ or only considered the change of HR. ${ }^{127}$ Jansen-Park et al. were able to implement the complete baroreceptor response in an M-MCL. The baroreceptor response was evaluated with a bleeding test where $450 \mathrm{~mL}$ was dispensed from the system. The M-MCL was able to compensate for some of the pressure drops, mean arterial pressure dropped from $90 \mathrm{mmHg}$ to $72.5 \mathrm{mmHg}$ and was increased to $82.5 \mathrm{mmHg}$. However, it was not able to fully recover to the mean arterial pressure.

For future MCLs, it is imperative to address these limitations of current MCLs. Integrating fully automated compliance chambers ${ }^{141}$ and resistance devices ${ }^{142}$ allows the implementation of the necessary autoregulation of the CVS. Parts of the CVS that are too difficult to model hydraulically can be implemented into the MCL with a numerical model, obtaining a flexible and cost-effective H-MCL.

\section{FUNDING ACKNOWLEDGEMENT}

Femke Capon is financially supported through EPSRC Doctoral Training Programme and magAssist Inc. to Brunel University London.

\section{CONFLICT OF INTEREST}

The authors declare that there is no conflict of interest.

\section{REFERENCES}

1. NHS. Organ Donation and Transplantation - Activity figures for the UK as at 9 April 2020. 2020.

2. Molina EJ, Shah P, Kiernan MS, et al. The Society of Thoracic Surgeons Intermacs 2020 Annual Report. Annals of Thoracic Surgery 2021; 111: 778-792.

3. Christiansen S, Klocke A, Autschbach R. Past, present, and future of long-term mechanical cardiac support in adults. Journal of Cardiac Surgery 2008; 23: 664-676. 
4. John R, Kamdar F, Liao K, et al. Improved Survival and Decreasing Incidence of Adverse Events With the HeartMate II Left Ventricular Assist Device as Bridge-to-Transplant Therapy. Annals of Thoracic Surgery 2008; 86: 1227-1235.

5. Jorde UP, Kushwaha SS, Tatooles AJ, et al. Results of the destination therapy post-food and drug administration approval study with a continuous flow left ventricular assist device. Journal of the American College of Cardiology 2014; 63: 1751-1757.

6. Petrou A, Granegger M, Meboldt M, et al. A Versatile Hybrid Mock Circulation for Hydraulic Investigations of Active and Passive Cardiovascular Implants. ASAIO journal 2019; 65: 495502.

7. Kolyva C, Biglino G, Pepper JR, et al. A Mock Circulatory System With Physiological Distribution of Terminal Resistance and Compliance: Application for Testing the Intra-Aortic Balloon Pump. Artificial Organs 2012; 36: 62-70.

8. Vandenberghe S, Segers P, Meyns B, et al. Unloading Effect of a Rotary Blood Pump Assessed by Mathematical Modeling. Artificial Organs 2003; 27: 1094-1101.

9. Schima $\mathrm{H}$, Baumgartner $\mathrm{H}$, Spitaler $\mathrm{F}$, et al. A modular mock circulation for hydromechanical studies on valves, stenoses, vascular grafts and cardiac assist devices. International Journal of Artificial Organs 1992; 15: 417-421.

10. Gehron J, Zirbes J, Bongert M, et al. Development and Validation of a Life-Sized Mock Circulatory Loop of the Human Circulation for Fluid-Mechanical Studies. ASAIO journal 2019; 65: 788-797.

11. Kado Y, Miyamoto T, Horvath DJ, et al. Development of a circulatory mock loop for biventricular device testing with various heart conditions. International Journal of Artificial Organs 2020; 43: 600-605.

12. Pillon $M$, Duffour $H$, Jufer $M$. In vitro experiments: Circulatory assist device interaction with a virtual cardiovascular system. In: Proceedings of the Annual International Conference of the IEEE Engineering in Medicine and Biology Society, EMBS. IEEE, 1992, pp. 740-741.

13. Baturalp TB, Ertas A. State of the Art Mock Circulation Loop and a Proposed Novel Design. In: Int'l Conf. Biomedical Engineering and Science. 2015, pp. 23-29.

14. Shi Y, Yang H. Mock circulatory test rigs for the in vitro testing of artificial cardiovascular organs. Journal of Medical Engineering and Technology 2019; 43: 223-234.

15. Shi $Y$, Korakianitis $T$, Li Z, et al. Structure and motion design of a mock circulatory test rig. Journal of Medical Engineering and Technology 2018; 42: 443-452.

16. Vollkron $\mathrm{M}$, Schima $\mathrm{H}$, Huber $\mathrm{L}$, et al. Interaction of the cardiovascular system with an implanted rotary assist device: Simulation study with a refined computer model. Artificial Organs 2002; 26: 349-359.

17. Shi Y, Korakianitis T, Bowles C. Numerical simulation of cardiovascular dynamics with different types of VAD assistance. Journal of Biomechanics 2007; 40: 2919-2933.

18. Pontrelli G, Rossoni E. Numerical modelling of the pressure wave propagation in the arterial flow. International Journal for Numerical Methods in Fluids 2003; 43: 651-671. 
19. Bavo AM, Rocatello G, lannaccone F, et al. Fluid-Structure Interaction Simulation of Prosthetic Aortic Valves: Comparison between Immersed Boundary and Arbitrary Lagrangian-Eulerian Techniques for the Mesh Representation. PLOS ONE 2016; 11: e0154517.

20. Fraser $\mathrm{KH}$, Taskin ME, Griffith BP, et al. The use of computational fluid dynamics in the development of ventricular assist devices. Medical Engineering and Physics 2011; 33: 263280.

21. Frank O. Die grundform des arteriellen pulses: Matehmatische Analyse. Zeitschriftfur Biologie 1899; 37: 483-526.

22. Westerhof N, Lankhaar JW, Westerhof BE. The arterial windkessel. Medical and Biological Engineering and Computing 2009; 47: 131-141.

23. Toy SM, Melbin J, Noordergraaf A. Reduced Models of Arterial Systems. IEEE Transactions on Biomedical Engineering 1985; BME-32: 174-176.

24. Westerhof N, Elzinga G, Sipkema P. An artificial arterial system for pumping hearts. Journal of applied physiology 1971; 31: 776-781.

25. Donovan FM. Design of a Hydraulic Analog of the Circulatory System for Evaluating Artificial Hearts. Biomaterials, Medical Devices, and Artificial Organs 1975; 3: 439-449.

26. Cornhill JF. An aortic left ventricular pulse duplicator used in testing prosthetic aortic heart valves. Journal of Thoracic and Cardiovascular Surgery 1977; 73: 550-558.

27. Pantalos GM, Koenig SC, Gillars KJ, et al. Characterization of an Adult Mock Circulation for Testing Cardiac Support Devices. ASAIO Journal 2004; 50: 37-46.

28. Arabia M, Akutsu T. A new test circulatory system for research in cardiovascular engineering. Annals of Biomedical Engineering 1984; 12: 29-48.

29. Ferrari G, Khir AW, Fresiello L, et al. Hybrid model analysis of intra-aortic balloon pump performance as a function of ventricular and circulatory parameters. Artificial Organs 2011; 35: 902-911.

30. Pantalos GM, lonan C, Koenig SC, et al. Expanded pediatric cardiovascular simulator for research and training. ASAIO Journal 2010; 56: 67-72.

31. Bjork VO, Intonti F, Meissl A. A mechanical pulse duplicator for testing prosthetic mitral and aortic valves. Thorax 1962; 17: 280-283.

32. Kolff WJ. Mock circulation to test pumps designed for permanent replacement of damaged hearts. Cleveland Clinic quarterly 1959; 26: 223-226.

33. Knierbein B, Reul H, Eilers R, et al. Compact mock loops of the systemic and pulmonary circulation for blood pump testing. International Journal of Artificial Organs 1992; 15: 40-48.

34. Orime Y, Takatani S, Tasai K, et al. In Vitro and In Vivo Validation Tests for Total Artificial Heart. Artificial Organs 1994; 18: 54-72.

35. Khalil HA, Kerr DT, Franchek MA, et al. Continuous flow total artificial heart: Modeling and feedback control in a mock circulatory system. ASAIO Journal 2008; 54: 249-255. 
36. Crosby JR, DeCook KJ, Tran PL, et al. A Physical Heart Failure Simulation System Utilizing the Total Artificial Heart and Modified Donovan Mock Circulation. Artificial Organs 2017; 41: E52-E65.

37. Nishida $\mathrm{M}$, Kosaka $\mathrm{R}$, Maruyama $\mathrm{O}$, et al. Long-term durability test of axial-flow ventricular assist device under pulsatile flow. Journal of Artificial Organs 2017; 20: 26-33.

38. Reul H, Tesch B, Schoenmackers J, et al. Hydromechanical simulation of systemic circulation. Medical \& Biological Engineering 1974; 12: 431-436.

39. Kikugawa D. Evaluation of cardiac function during left ventricular assist by a centrifugal blood pump. Artificial Organs 2000; 24: 632-635.

40. Scotten LN, Walker DK, Brownlee RT. Construction and evaluation of a hydromechanical simulation facility for the assessment of mitral valve prostheses. Journal of Medical Engineering and Technology 1979; 3: 11-18.

41. Verdonck P, Kleven A, Verhoeven R, et al. Computer-controlled in vitro model of the human left heart. Medical \& Biological Engineering \& Computing 1992; 19: 656-659.

42. Papaioannou TG, Mathioulakis DS, Nanas JN, et al. Arterial compliance is a main variable determining the effectiveness of intra-aortic balloon counterpulsation: Quantitative data from an in vitro study. Medical Engineering and Physics 2002; 24: 279-284.

43. Liu $\mathrm{Y}$, Allaire $\mathrm{P}, \mathrm{Wu} \mathrm{Y}$, et al. Construction of an artificial heart pump performance test system. Cardiovascular Engineering 2006; 6: 151-158.

44. Sénage $T$, Février $D$, Michel $M$, et al. A mock circulatory system to assess the performance of continuous-flow left ventricular assist devices (LVADs): Does axial flow unload better than centrifugal LVAD? ASAIO Journal 2014; 60: 140-147.

45. Love HC, Timms DL, Nestler F, et al. A mock circulatory loop for designing and evaluating total artificial hearts. In: Conf Proc IEEE Eng Med Biol Soc. IEEE, 2014, pp. 5667-5670.

46. Hsu P-L, Hatam N, Unterkofler J, et al. Selective reduction of afterload in right heart assist therapy: A mock loop study. Interactive Cardiovascular and Thoracic Surgery 2014; 19: 76-81.

47. Legendre D, Fonseca J, Andrade A, et al. Mock circulatory system for the evaluation of left ventricular assist devices, endoluminal prostheses, and vascular diseases. Artificial Organs 2008; 32: 461-467.

48. Karabegovic A, Hinteregger M, Janeczek $C$, et al. A systemic mock circulation for in-vitro testing of a pneumatically operated left ventricular assist device. IFAC Proceedings Volumes. 2014; 47: 8409-8414.

49. Wu Y, Allaire PE, Tao G, et al. Modeling, estimation, and control of human circulatory system with a left ventricular assist device. IEEE Transactions on Control Systems Technology 2007; 15: 754-767.

50. Jhun C-S, Reibson JD, Cysyk JP. Effective ventricular unloading by left ventricular assist device varies with stage of heart failure: Cardiac simulator study. ASAIO Journal 2011; 57: 407-413. 
51. Papaioannou TG, Mathioulakis DS, Tsangaris SG. Simulation of systolic and diastolic left ventricular dysfunction in a mock circulation: the effect of arterial compliance. Journal of Medical Engineering and Technology 2003; 27: 85-89.

52. Miyamoto T, Horvath DJ, Horvath DW, et al. Simulated Performance of the Cleveland Clinic Continuous-Flow Total Artificial Heart Using the Virtual Mock Loop. ASAIO Journal 2019; 65: 565-572.

53. Shehab S, Allida SM, Newton PJ, et al. Valvular Regurgitation in a Biventricular Mock Circulatory Loop. ASAIO Journal 2019; 65: 551-557.

54. Mouret F, Garitey V, Gandelheid T, et al. A new dual activation simulator of the left heart that reproduces physiological and pathological conditions. Medical and Biological Engineering and Computing 2000; 38: 558-561.

55. Timms D, Hayne M, McNeil K, et al. A Complete Mock Circulation Loop for the Evaluation of Left, Right, and Biventricular Assist Devices. Artificial Organs 2005; 29: 564-572.

56. Timms D, Hayne M, Tan A, et al. Evaluation of left ventricular assist device performance and hydraulic force in a complete mock circulation loop. Artificial Organs 2005; 29: 573-580.

57. Wang $Y$, Smith PA, Timms DL, et al. Hemodynamic effects of synchronizing an intra-aortic VAD in reverse-rotation control with left ventricle: A mock loop study. In: Annu Int Conf IEEE Eng Med Biol Soc. IEEE, 2016, pp. 4300-4304.

58. Tsuboko Y, Shiraishi $Y$, Matsuo S, et al. Effect of right atrial contraction on prosthetic valve function in a mechanical pulmonary circulatory system. Journal of Biomechanical Science and Engineering 2016; 11: 1-9.

59. Zhou J, Armstrong GP, Medvedev AL, et al. Numerical model of the cardiovascular system with left ventricle assist device. ASAIO Journal 1999; 45: 83-89.

60. Ferrari G, Lazzari C De, Mimmo R, et al. Mock circulatory system for in vitro reproduction of the left ventricle, the arterial tree and their interaction with a left ventricular assist device. Journal of Medical Engineering and Technology 1994; 18: 87-95.

61. Zannoli R, Corazza I, Branzi A. Mechanical simulator of the cardiovascular system. Physica Medica 2009; 25: 94-100.

62. Fukamachi K, Shiose A, Massiello A, et al. Preload sensitivity in cardiac assist devices. Annals of Thoracic Surgery 2013; 95: 373-380.

63. Baloa LA, Boston JR, Antaki JF. Elastance-based control of a mock circulatory system. Annals of Biomedical Engineering 2001; 29: 244-251.

64. Loh M, Yu Y-C. Feedback control design for an elastance-based mock circulatory system. In: Proc Am Control Conf. 2004, pp. 1639-1644.

65. Shi Y, Lawford P V., Hose DR. Numerical modeling of hemodynamics with pulsatile impeller pump support. Annals of Biomedical Engineering 2010; 38: 2621-2634.

66. Korakianitis T, Shi Y. Numerical simulation of cardiovascular dynamics with healthy and diseased heart valves. Journal of Biomechanics 2006; 39: 1964-1982. 
67. Sagawa $\mathrm{K}$, Maughan $\mathrm{L}$, Suga $\mathrm{H}$, et al. Cardiac contraction and the pressure-volume relationship. New Yorik: Oxfrod University Press, 1988.

68. Yokoyama Y, Kawaguchi $\mathrm{O}$, Shinshi $\mathrm{T}$, et al. A new pulse duplicator with a passive fill ventricle for analysis of cardiac dynamics. Journal of Artificial Organs 2010; 13: 189-196.

69. Burkhoff D, Mirsky I, Suga H. Assessment of systolic and diastolic ventricular properties via pressure-volume analysis: A guide for clinical, translational, and basic researchers. American Journal of Physiology - Heart and Circulatory Physiology 2005; 289: H501-H512.

70. Vandenberghe $S$, Segers $P$, Steendijk $P$, et al. Modeling ventricular function during cardiac assist: does time-varying elastance work? ASAIO journal 2006; 52: 4-8.

71. Koenig SC, Pantalos GM, Gillars KJ, et al. Hemodynamic and Pressure-Volume Responses to Continuous and Pulsatile Ventricular Assist in an Adult Mock Circulation. ASAIO Journal 2004; 50: 15-24.

72. Colacino FM, Moscato F, Piedimonte $F$, et al. A modified elastance model to control mock ventricles in real-time: Numerical and experimental validation. ASAIO Journal 2008; 54: $563-$ 573.

73. Gregory SD, Stevens M, Timms D, et al. Replication of the Frank-Starling response in a mock circulation loop. In: Proceedings of the Annual International Conference of the IEEE Engineering in Medicine and Biology Society, EMBS. IEEE, 2011, pp. 6825-6828.

74. Timms DL, Gregory SD, Greatrex NA, et al. A Compact Mock Circulation Loop for the In Vitro Testing of Cardiovascular Devices. Artificial Organs 2011; 35: 384-391.

75. Khir AW, Swalen MJ, Segers P, et al. Hemodynamics of a Pulsatile Left Ventricular Assist Device Driven by a Counterpulsation Pump in a Mock Circulation. Artificial Organs 2006; 30: 308-312.

76. Knoops PGM, Biglino G, Hughes AD, et al. A Mock Circulatory System Incorporating a Compliant 3D-Printed Anatomical Model to Investigate Pulmonary Hemodynamics. Artificial Organs 2017; 41: 637-646.

77. Boone AC, Gregory SD, Wu EL, et al. Evaluation of an intraventricular balloon pump for shortterm support of patients with heart failure. Artificial Organs 2019; 43: 860-869.

78. Laumen M, Kaufmann T, Timms D, et al. Flow analysis of ventricular assist device inflow and outflow cannula positioning using a naturally shaped ventricle and aortic branch. Artificial Organs 2010; 34: 798-806.

79. Gregory S, Timms D, Pearcy MJ, et al. A naturally shaped silicone ventricle evaluated in a mock circulation loop: A preliminary study. Journal of Medical Engineering and Technology 2009; 33: 185-191.

80. May-Newman K, Marquez-Maya N, Montes R, et al. The effect of inflow cannula angle on the intraventricular flow field of the left ventricular assist device-assisted heart: An in vitro flow visualization study. ASAIO Journal 2019; 65: 139-147.

81. Tanné $\mathrm{D}$, Bertrand $\mathrm{E}, \mathrm{Kadem} \mathrm{L}$, et al. Assessment of left heart and pulmonary circulation flow dynamics by a new pulsed mock circulatory system. Experiments in Fluids 2010; 48: 837-850. 
82. Geier A, Kunert A, Albrecht G, et al. Influence of Cannulation Site on Carotid Perfusion During Extracorporeal Membrane Oxygenation in a Compliant Human Aortic Model. Annals of Biomedical Engineering 2017; 45: 2281-2297.

83. Peter L, Noury N, Cerny M. The New Approach for The Model of Cardiovascular System. IFACPapersOnLine 2018; 51: 48-53.

84. Litwak KN, Koenig SC, Cheng RC, et al. Ascending aorta outflow graft location and pulsatile ventricular assist provide optimal hemodynamic support in an adult mock circulation. Artificial Organs 2005; 29: 629-635.

85. Kolyva C, Pepper JR, Khir AW. Newly Shaped Intra-Aortic Balloons Improve the Performance of Counterpulsation at the Semirecumbent Position: An In Vitro Study. Artificial Organs 2016; 40: E146-E157.

86. Mueller I, Jansen-Park SH, Neidlin M, et al. Design of a right ventricular mock circulation loop as a test bench for right ventricular assist devices. Biomedizinische Technik 2017; 62: 131137.

87. D'Souza GA, Taylor MD, Banerjee RK. Methodology for hemodynamic assessment of a threedimensional printed patient-specific vascular test device. Journal of Medical Devices, Transactions of the ASME 2019; 13: 1-8.

88. King JM, Bergeron CA, Taylor CE. Development of an adaptive pulmonary simulator for in vitro analysis of patient populations and patient-specific data. Computer Methods and Programs in Biomedicine 2018; 161: 93-102.

89. Geven MCF, Bohté VN, Aarnoudse WH, et al. A physiologically representative in vitro model of the coronary circulation. Physiological Measurement 2004; 25: 891-904.

90. De Lazzari C, Darowski M, Ferrari G, et al. Modelling in the study of interaction of Hemopump device and artificial ventilation. Computers in Biology and Medicine 2006; 36: 1235-1251.

91. Giridharen GA, Ewert DL, Pantalos GM, et al. Left Ventricular and Myocardial Perfusion Responses to Volume Unloading and Afterload Reduction in a Computer Simulation. ASAIO Journal 2004; 50: 512-518.

92. Rezaienia MA, Paul G, Avital EJ, et al. In-vitro investigation of the hemodynamic responses of the cerebral, coronary and renal circulations with a rotary blood pump installed in the descending aorta. Medical Engineering and Physics 2017; 40: 2-10.

93. Rezaienia MA, Rahideh A, Alhosseini Hamedani B, et al. Numerical and In Vitro Investigation of a Novel Mechanical Circulatory Support Device Installed in the Descending Aorta. Artificial Organs 2015; 39: 502-513.

94. Hsu PL, Bruch J, Mcmahon R. A Controller for a Miniature Intra-Aortic Ventricular Assist Device. Artificial Organs 2011; 35: 282-287.

95. Gregory SD, Pauls JP, Wu EL, et al. An advanced mock circulation loop for in vitro cardiovascular device evaluation. Artificial Organs 2020; 00: 1-13.

96. Clark WD, Eslahpazir BA, Argueta-Morales IR, et al. Comparison Between Bench-Top and Computational Modelling of Cerebral Thromboembolism in Ventricular Assist Device Circulation. Cardiovascular Engineering and Technology 2015; 6: 242-255. 
97. Bozkurt S. Effect of Cerebral Flow Autoregulation Function on Cerebral Flow Rate Under Continuous Flow Left Ventricular Assist Device Support. Artificial Organs 2018; 42: 800-813.

98. Ferrari G, Kozarski M, Lazzari C, et al. Artificial Heart and Cardiac Assist Devices A hybrid ( numerical-physical ) model of the left ventricle. The International Journal of Artificial Organs 2001; 24: 456-462.

99. Kozarski M, Ferrari GF, Clemente F, et al. A hybrid mock circulatory system: Development and testing of an electro-hydraulic impedance simulator. International Journal of Artificial Organs 2003; 26: 53-63.

100. Ferrari GF, Kozarski M, De Lazzari C, et al. Modelling of cardiovascular system: Development of a hybrid (numerical-physical) model. International Journal of Artificial Organs 2003; 26: 1104-1114.

101. Ferrari G, De Lazzari C, Kozarski M, et al. A hybrid mock circulatory system: Testing a prototype under physiologic and pathological conditions. ASAIO Journal 2002; 48: 487-494.

102. Gwak K-W. Design and Evaluation of Cardiovascular Impedance Simulator Considering Mechanical Limits. Journal of the Korean Society for Precision Engineering 2008; 25: 151-159.

103. Ochsner G, Amacher R, Amstutz A, et al. A novel interface for hybrid mock circulations to evaluate ventricular assist devices. IEEE Transactions on Biomedical Engineering 2013; 60 : 507-516.

104. Nestler F, Bradley AP, Wilson SJ, et al. A Hybrid Mock Circulation Loop for a Total Artificial Heart. Artificial Organs 2014; 38: 775-782.

105. Felipini CL, De Andrade AJP, Lucchi JC, et al. An electro-fluid-dynamic simulator for the cardiovascular system. Artificial Organs 2008; 32: 349-354.

106. Telyshev D, Pugovkin A, Selishchev S, et al. Hybrid mock circulatory loop for training and study purposes. In: 2018 Ural Symposium on Biomedical Engineering, Radioelectronics and Information Technology (USBEREIT). 2018, pp. 29-32.

107. Mirzaei E, Farahmand M, Kung E. An algorithm for coupling multibranch in vitro experiment to numerical physiology simulation for a hybrid cardiovascular model. International Journal for Numerical Methods in Biomedical Engineering 2020; 36: 1-4.

108. Hanson BM, Levesley MC, Watterson K, et al. Hardware-in-the-loop-simulation of the cardiovascular system, with assist device testing application. Medical Engineering and Physics 2007; 29: 367-374.

109. Alazmani A, Keeling DG, Walker PG, et al. Introducing a hardware-in-the-loop simulation of the cardiovascular system. In: Proceedings of the IEEE RAS and EMBS International Conference on Biomedical Robotics and Biomechatronics. IEEE, 2012, pp. 153-158.

110. Colacino FM, Moscato F, Piedimonte F, et al. A modified elastance model to control mock ventricles in real-time: Numerical and experimental validation. ASAIO Journal 2008; 54: 563573.

111. Urbaszek A, Schaldach M. A numerical heart and circulation model to simulate hemodynamics for rate-responsive pacing. In: Power $\mathrm{H}$, editor. Bio-fluid mechanics. Southampton/Boston: Computational Mechanics Publications. 1995, pp. 129-60. 
112. Darowski M, Kozarski M, Ferrari G, et al. A new hybrid (hydro-numerical) model of the circulatory system. Bulletin of the Polish Academy of Sciences: Technical Sciences 2013; 61: 993-1003.

113. Ferrari GF, Kozarski M, De Lazzari C, et al. Development of a hybrid (numerical-hydraulic) circulatory model: Prototype testing and its response to IABP assistance. International Journal of Artificial Organs 2005; 28: 750-759.

114. Fresiello L, Khir AW, Di Molfetta A, et al. Effects of Intra-Aortic Balloon Pump Timing on Baroreflex Activities in a Closed-Loop Cardiovascular Hybrid Model. Artificial Organs 2013; 37: 237-247.

115. Fresiello L, Zieliński K, Jacobs S, et al. Reproduction of continuous flow left ventricular assist device experimental data by means of a hybrid cardiovascular model with baroreflex control. Artificial Organs 2014; 38: 456-468.

116. Ursino M, Giulioni M, Lodi CA. Relationships among cerebral perfusion pressure, autoregulation, and transcranial Doppler waveform: A modeling study. J Neurosurg; 89: 25566.

117. Cuenca-Navalon E, Finocchiaro T, Laumen M, et al. Design and Evaluation of a Hybrid Mock Circulatory Loop for total Artificial Heart Testing. The International Journal of Artificial Organs 2014; 37: 71-80.

118. Ursino M, Antonucci M, Belardinelli E. Role of active changes in venous capacity by the carotid baroreflex : analysis with a mathematical model. Am J Physiol 1994; 267: H2531H2546.

119. Mushi S, Yu YC. Control of a mock circulatory system to simulate the short-term baroreflex. In: American Control Conference. 2008, pp. 844-849.

120. Mushi S, Yu YC. Identification of fluidic element models to simulate the short-term baroreflex. Proceedings of the IEEE Conference on Decision and Control 2006; 5738-5743.

121. Jansen-Park SH, Mahmood MN, Müller I, et al. Effects of Interaction Between Ventricular Assist Device Assistance and Autoregulated Mock Circulation Including Frank-Starling Mechanism and Baroreflex. Artificial Organs 2016; 40: 981-991.

122. Vaes $\mathrm{M}$, Rutten $\mathrm{M}$, Molengraft $\mathrm{R}$ van de, et al. Left-ventricular assist device evaluation with a model-controlled mock circulation. In: Summer Bioengineering Conference. Keystone, Colorado, USA, 2007, pp. 1-2.

123. Van Roon AM, Mulder LJM, Althaus M, et al. Introducing a baroreflex model for studying cardiovascular effects of mental workload. Psychophysiology 2004; 41: 961-981.

124. Bozkurt S, Safak KK. Evaluating the hemodynamical response of a cardiovascular system under support of a continuous flow left ventricular assist device via numerical modeling and simulations. Computational and Mathematical Methods in Medicine 2013; 2013: 1-12.

125. Bonnemain J, Malossi ACl, Lesinigo $\mathrm{M}$, et al. Numerical simulation of left ventricular assist device implantations: Comparing the ascending and the descending aorta cannulations. Medical Engineering and Physics 2013; 35: 1465-1475. 
126. Ding X, Frank PM. Modelling, Control and Monitoring of Circulatory Systems with an Artificial Heart. International Journal of Quality \& Reliability Management 1994; 11: 41-50.

127. Schampaert S, Pennings KAMA, Van De Molengraft MJG, et al. A mock circulation model for cardiovascular device evaluation. Physiological Measurement 2014; 35: 687-702.

128. Wu Y, Allaire $P$, Tao G, et al. An Advanced Physiological Controller Design for a Left Ventricular Assist Device to Prevent Left Ventricular Collapse. Artificial Organs 2003; 27: 926930.

129. Papaioannou TG, Mathioulakis DS, Stamatelopoulos KS, et al. New aspects on the role of blood pressure and arterial stiffness in mechanical assistance by intra-aortic balloon pump: In-vitro data and their application in clinical practice. Artificial Organs 2004; 28: 717-727.

130. Rezaienia MA, Paul G, Avital E, et al. In-vitro investigation of cerebral-perfusion effects of a rotary blood pump installed in the descending aorta. Journal of Biomechanics 2016; 49: 1865-1872.

131. Yuan N, Arnaoutakis GJ, George TJ, et al. The spectrum of complications following left ventricular assist device placement. Journal of Cardiac Surgery 2012; 27: 630-638.

132. Gwak K, Paden BE, Antaki JF, et al. Cardiovascular Impedance Simulator. IEEE Transactions on Biomedical Engineering 2010; 57: 1176-1183.

133. Nestler F, Timms DL, Stevens M, et al. Investigation of the inherent left-right flow balancing of rotary total artificial hearts by means of a resistance box. Artificial Organs 2020; 44: 584-593.

134. Bozkurt S. Effect of Cerebral Flow Autoregulation Function on Cerebral Flow Rate Under Continuous Flow Left Ventricular Assist Device Support. Artificial Organs 2018; 42: 800-813.

135. Rezaienia MA, Paul G, Avital EJ, et al. In-vitro investigation of the hemodynamic responses of the cerebral, coronary and renal circulations with a rotary blood pump installed in the descending aorta. Medical Engineering and Physics 2017; 40: 2-10.

136. Tsay J, Pinkhas D, Lee BC, et al. Worsening Renal Function in Cardiac Mechanical Support. Heart Lung and Circulation 2020; 1-9.

137. Wang $Y$, Smith PA, De-Sciscio $P$, et al. Replication of pressure-volume loop with controllable ESPVR and EDPVR curves on a personalized mock circulatory loop based on elastance function. In: 39th Annual International Conference of the IEEE Engineering in Medicine and Biology Society (EMBC). IEEE, 2017, pp. 1282-1286.

138. Gohean JR, George MJ, Chang KW, et al. Preservation of native aortic valve flow and full hemodynamic support with the TORVAD using a computational model of the cardiovascular system. ASAIO Journal 2015; 61: 259-265.

139. Huang F, Ruan X, Zou J, et al. A fast building and effective hydraulic pediatric mock circulatory system for the evaluation of a left ventricular assist device. ASAIO Journal 2013; 59: 575-585.

140. Yu YC, Gopalakrishnan S. Elastance control of a mock circulatory system for ventricular assist device test. Proceedings of the American Control Conference 2009; 1009-1014.

141. Taylor CE, Miller GE. Mock Circulatory Loop Compliance Chamber Employing a Novel RealTime Control Process. Journal of Medical Devices, Transactions of the ASME 2012; 6: 1-8. 
142. Taylor CE, Miller GE. Implementation of an Automated Peripheral Resistance Device in a Mock Circulatory Loop With Characterization of Performance Values Using Simulink Simscape and Parameter Estimation. Journal of Medical Devices, Transactions of the ASME 2012; 6: 17.

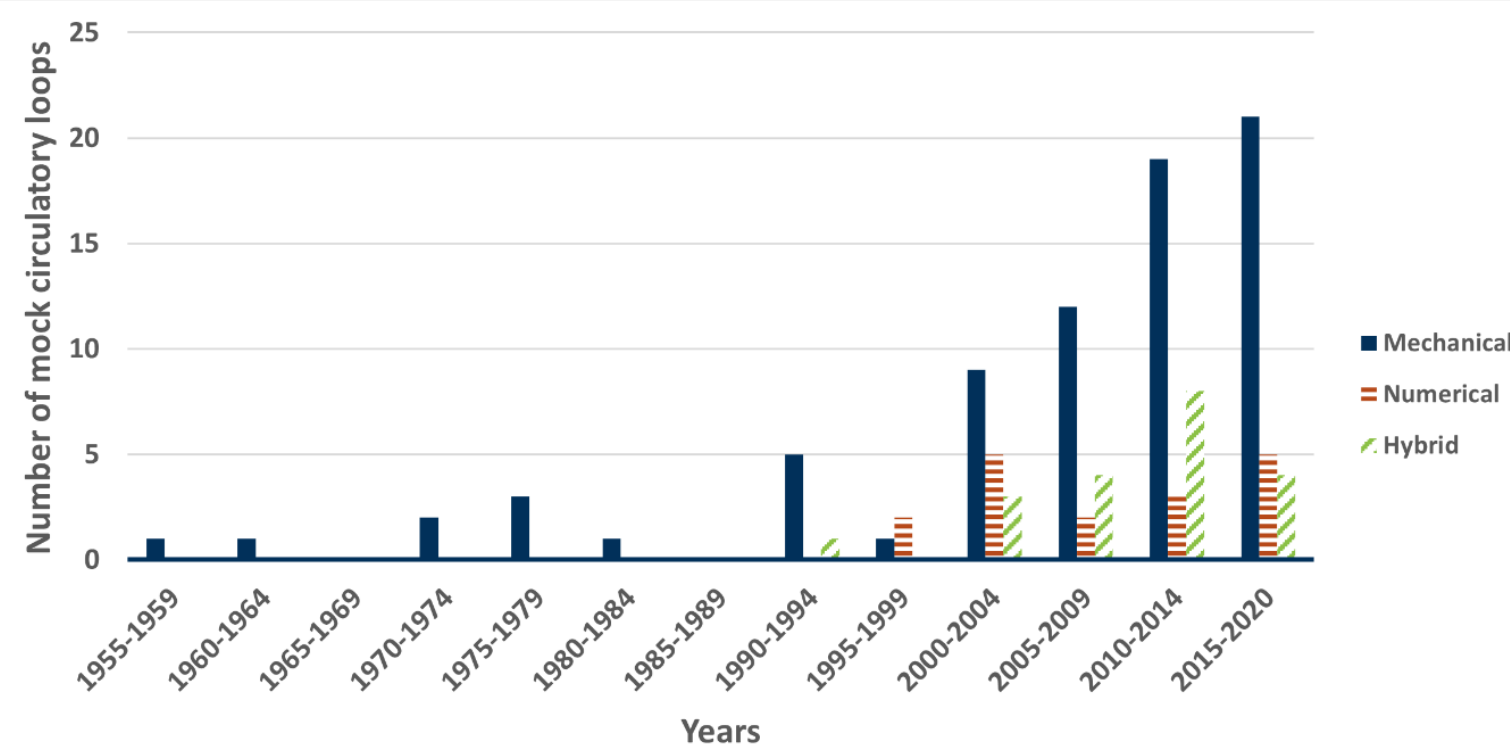

Figure 1: The number of the three types of mock circulatory systems developed over the years.
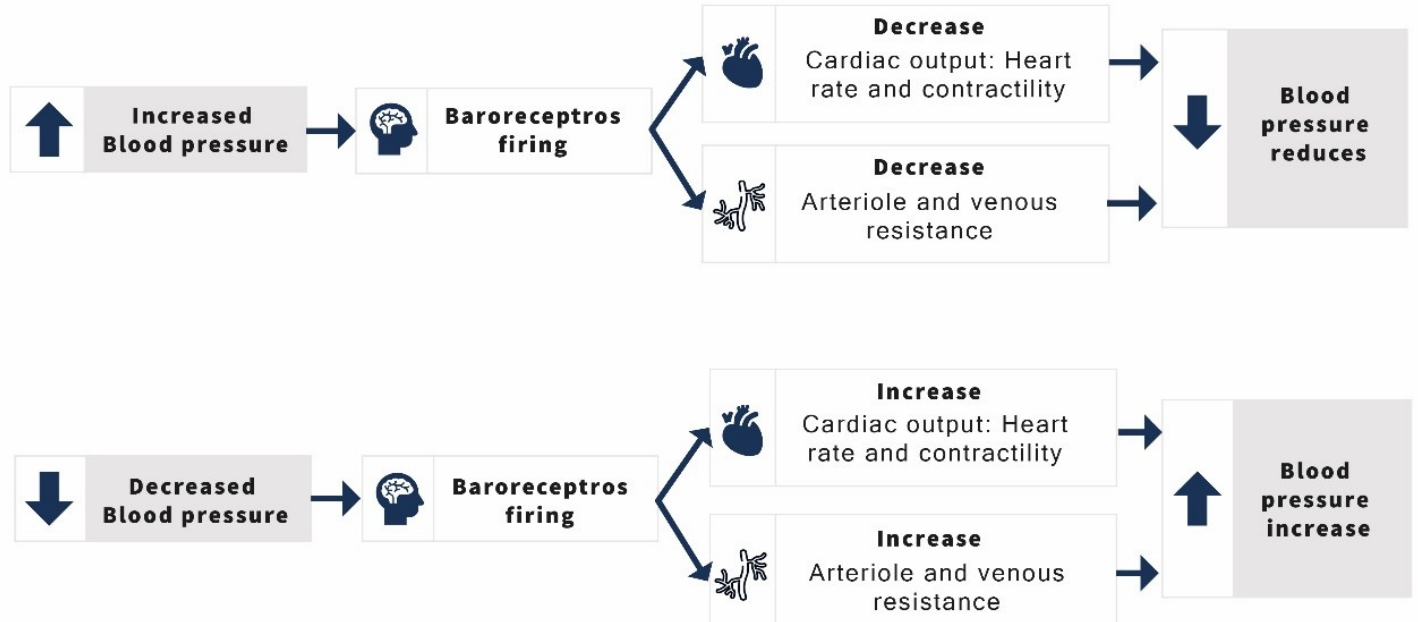

Figure 2: Response of the baroreceptors to a sudden decrease or increase of blood pressure. The baroreceptors can control the cardiac output of the heart and the resistance of the peripheral and systemic arteries. 


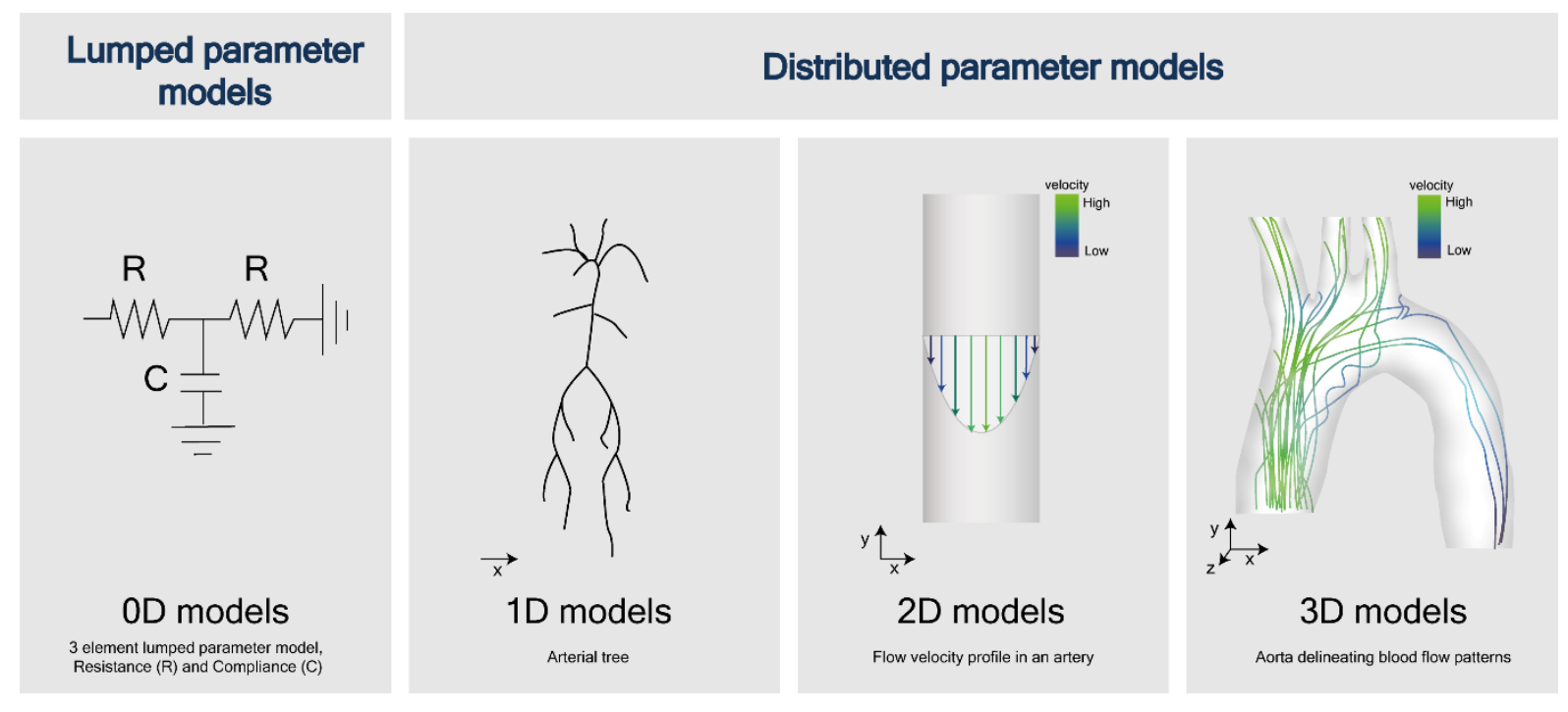

Figure 3: Comparison between lumped parameter model and the distributed parameter models. The focus of numerical models in this review is on lumped parameter models.

\section{IDENTIFICATION}

Articles identified through search on Scopus database on 25 September 2020

from the earliest date possible:

$$
n=461
$$

\section{IDENTIFICATION}

Additional articles identified through backward reference searching:

$$
n=65
$$

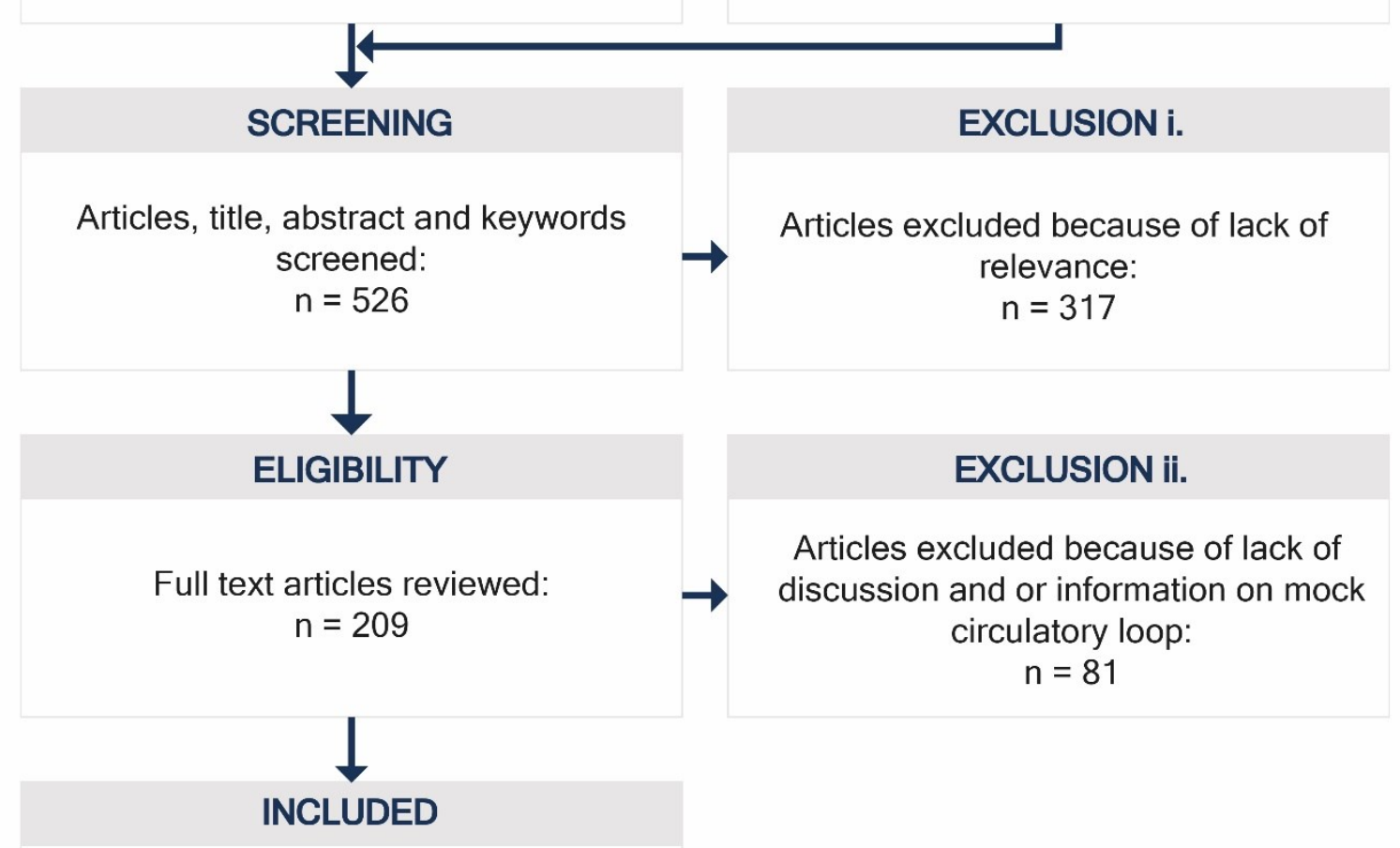

Articles included:

$\mathrm{n}=209$ 
Figure 4: Flowchart of the literature search. A staring set of papers was identified using SCOPUS. Using backwards referencing an additional 65 articles were added. Articles were screened on their title, abstract and keywords. Full-text articles were reviewed and included depending on their relevant information to mock circulatory loops.

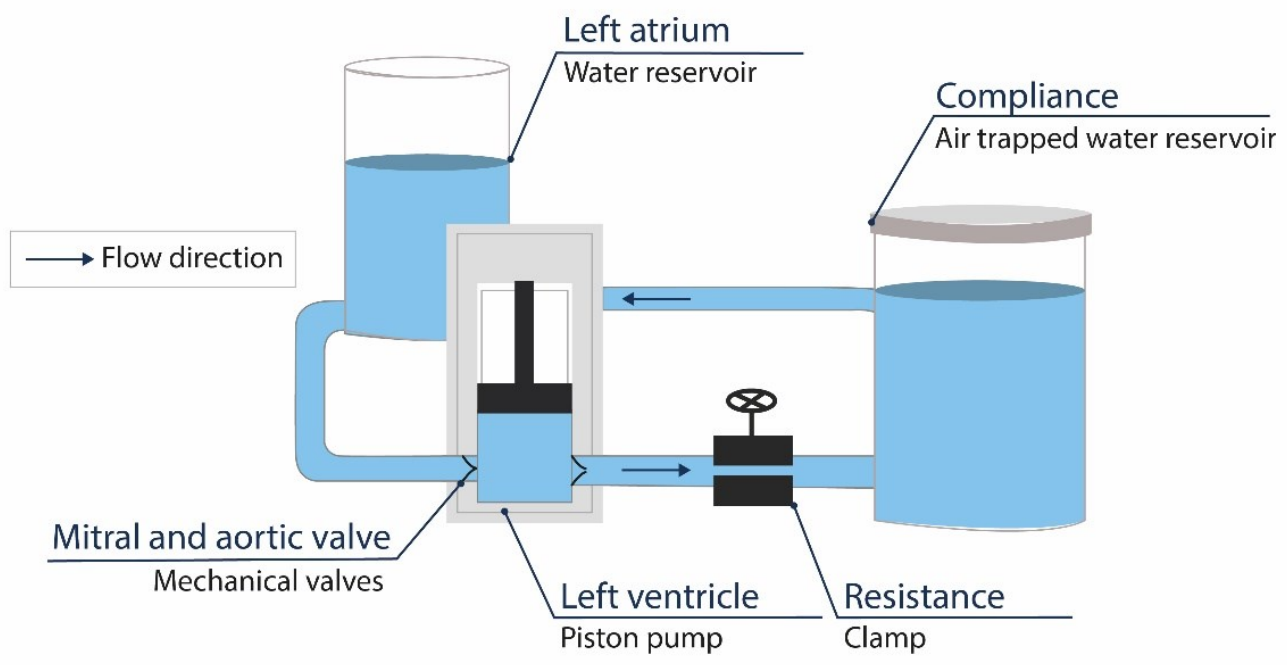

Figure 5: Typical mechanical mock circulatory set-up in which the systemic part of the circulation is simulated with a left ventricle, variable resistance, variable compliance and left atrium. 